\title{
CORRELATION OF OXIDATIVE STRESS MARKERS MALONDIALDEHYDE (MDA), ANTIOXIDANT VITAMINS A, E, AND C WITH GLYCATED HEMOGLOBIN (HBA1C) LEVELS IN TYPE 2 DIABETES MELLITUS
}

\author{
ABD ELGADIR A. ALTOUM, AHMED L. OSMAN, ASAAD MA. BABKER* \\ Department of Medical Laboratory Sciences, College of Health Sciences, Gulf Medical University, Ajman, UAE. Email: azad.88@hotmail.com \\ Received: 01 January 2018, Revised and Accepted: 31 January 2018
}

ABSTRACT

Objective: The purpose of this study was to understand the relationship between oxidative stress markers malondialdehyde (MDA), antioxidant Vitamins A, E, and C and the glycated hemoglobin levels with Type 2 diabetes mellitus.

Methods: The current study is a cross-sectional study group, comprised no diabetic individuals (100 healthy) as control groups and diabetic patients (300) as cases groups, attending the Khartoum - Sudan for routine follow-up during 2013-2015. The data were collected with the help of structured questionnaire and direct interview to collect information. Blood specimens were collected from both groups, and plasma levels of MDA, serum zinc, antioxidant Vitamins (A, E, and C), and glycated hemoglobin (HbA1c) were determined. Odds ratio and the $95 \%$ confidence interval (95\% CI) were calculated for the presence of mutation between cases and controls and analyzed by SPSS program, version 13.

Results: The results of this study indicate a highly significant difference between the means of HbA1c\% of the test group ( $\mathrm{n}=300$ ) and the control group $(\mathrm{n}=100)$. Mean \pm SD: $7.5 \pm 1.4$ versus $4.9 \pm 0.3$, respectively ( $\mathrm{p}=0.001)$. Significant positive correlation between HbA1c and MDA $(\mathrm{p}=0.003)$. Significant correlation between $\mathrm{HbA1} \mathrm{c} \%$ and plasma Vitamins A, E, and C of the test group, respectively ( $\mathrm{p}=0.002),(\mathrm{p}=0.0008)$, and $(\mathrm{p}=0.01)$.

Conclusion: There was significant correlation between HbA1c\% with Malondialdehyde (MDA) and antioxidant Vitamins (A, C, and E).

Keywords: Type 2 diabetes mellitus, Glycated hemoglobin, Malondialdehyde, Antioxidant vitamins.

(c) 2018 The Authors. Published by Innovare Academic Sciences Pvt Ltd. This is an open access article under the CC BY license (http://creativecommons. org/licenses/by/4. 0/) DOI: http://dx.doi.org/10.22159/ajpcr.2018.v11i5.24548

\section{INTRODUCTION}

Diabetes mellitus (DM) is a metabolic disorder associated with many complications includes hyperglycemia, oxidative stress, and inflammation [1]. There are two types of DM called Types 1 and 2. The most frequent one is Type 2 DM (T2DM), which is a disease that characterized by high levels of blood glucose. The prevalence of Type 2 diabetes is increasing health burden in both developed and underdeveloped countries [2]. Stress is recognized as one of the risk factors that cause the development of Type 2 diabetes. During the development of the disease, hyperglycemia causes increase the production of free radicals, especially reactive oxygen species, for all tissues from glucose autoxidation and protein glycosylation [3]. Antioxidant defense mechanisms include both enzymatic and nonenzymatic strategies. The most common antioxidants include the Vitamins A, C, E, and the tripeptide glutathione, and the enzymes superoxide dismutase, malondialdehyde (MDA), catalase, glutathione peroxidase, and glutathione reeducates [4]. Glycated $\mathrm{Hb}$ level is a useful tool used in diagnosis of diabetes progression. Elevated glycosylated hemoglobin (HbA1c) in the blood is an indicator of chronically raised blood glucose concentrations that are used as a method of identifying people at risk of developing diabetes or as a marker of poor control in diagnosed diabetics [5]. Glycated hemoglobin causes an increase of highly reactive free radicals inside blood cells. This leads to blood cell aggregation and increased blood viscosity which results in impaired blood flow [6]. There is the significant correlation between blood glucose and HbA1c values [7]. Hence, the aim of the current study was to correlate glycated hemoglobin with MDA, antioxidant Vitamins A, E, and C in Type 2 diabetes.

\section{METHODS}

A total of 100 healthy subjects were control group with mean fasting blood sugar (FBS) $5.61=\mathrm{m} \mathrm{mol} / \mathrm{L}$. The age ranged from 22 to 78 years old. The mean age average was 50.1 years. Type 2 diabetic patients were 300; the ages ranged from 30 to 80 years old. The mean age average was 51.2 years. All samples were in a state of fasting for $12 \mathrm{~h}$ before drawing blood. This study was conducted in Khartoum state in advanced diagnostic center in Bahri from May 2013 to August 2015. HbA1c percentage level was determined by method based on boronate affinity chromatography using NYCOCARD READER II - AXIS-SHIELD PoC AS NO-0504 Oslo, Norway, rapid in vitro test for the measurement of glycated hemoglobin (HbA1c) \% in human whole blood. The machine (NYCOCARD READER II) is traceable to the International Federation of Clinical Chemistry reference method for the measurement of HbA1c, and its measuring range $3-18 \% \mathrm{HbA} 1 \mathrm{c}$ [8]. MDA serum was mixed with $20 \%$ TCA and allowed to stand for $10 \mathrm{~min}$. After that, $0.05 \mathrm{~m}$ H2So 4 and TBA were added. The mixture was mixed and placed in $70^{\circ} \mathrm{C}$ water bath for $30 \mathrm{~min}$. The resulting chromogen was extracted with $\mathrm{n}$-butanol and centrifuged at $2000 \mathrm{rpm} / \mathrm{min}$ and measured against butanol blank at $532 \mathrm{~nm}$ excitation and $553 \mathrm{~nm}$ emissions by spectrophotometer [9]. Vitamins A, E, and C antioxidant were assayed by chromatography measurements were made using Hewlett-Packard (Wald born, Germany) model 1050 pump system, Water 717 plus Auto Sampler (Mil Ford, MA, USA), SPD-10 AV VP (Shimadzu Kyoto, Japan), and an HP-3365 series II Chemstation. The body mass index is a statistic developed by Adolphe Quetelet in the 1900s for evaluating body mass by bodyweight in kilograms divided by height in meters squared.

\section{Statistical analysis}

Statistical Package for the Social Sciences SPSS (version 13) computer software was used for data analysis. The means and standard deviations of variable calculated and t-test was used for comparison (significant level was set at $\mathrm{p} \leq 0.05$ ). 


\section{RESULTS}

The results of this study indicate a highly significant difference between the means of $\mathrm{HbA} 1 \mathrm{c} \%$ of the test group and their FBS Fig. 1. Fig. 2 shows significant moderate positive correlation between HbA1c and plasma MDA of the test group ( $p=0.003$ ). Fig. 3 shows significant a strong negative correlation between $\mathrm{HbA} 1 \mathrm{c} \%$ and plasma Vitamin A of the test group ( $p=0.002)$. Fig. 4 shows significantly strong negative correlation between HbA1c and plasma Vitamin C of the test group ( $\mathrm{p}=0.01)$. Fig. 5 shows significantly strong negative correlation between HbA1c and plasma Vitamin E of the test group ( $\mathrm{p}=0.0008)$.

\section{DISCUSSION}

The results of our study show a highly significant difference between the means of $\mathrm{HbA} 1 \mathrm{c} \%$ of the test group and the control group, this finding is similar to several previous studies recommend using of HbA1c as a potential biomarker for predicting dyslipidemia in Type 2 diabetic patients in addition to glycemic control [10-13]. In the present study, we found positive correlation between glycated hemoglobin and MDA, this results are consistent with the work of Salem et al., stated that, MDA showed statistically significant positive correlation with $\mathrm{HbA} 1 \mathrm{c}$ and concluded that trace elements and MDA

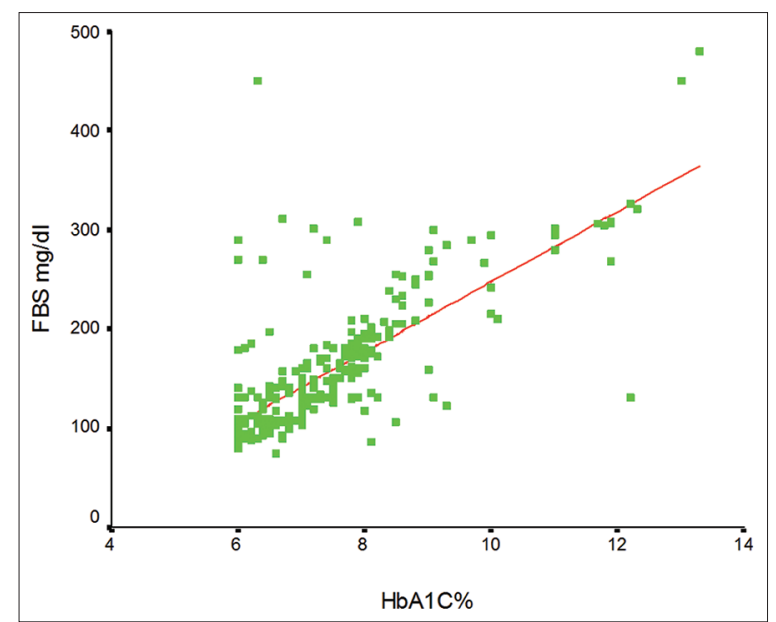

Fig. 1: Scatter plot shows the relationship between $\mathrm{HbA1c} \%$ and serum fasting blood sugar (FBS) of the test group $(n=300)$ $(\mathrm{r}=0.74, \mathrm{p}=0.0001 *)$ *Significant relationship between the changes in $\mathrm{HbA1c} \%$ and FBS among the test group $(p<0.05)$

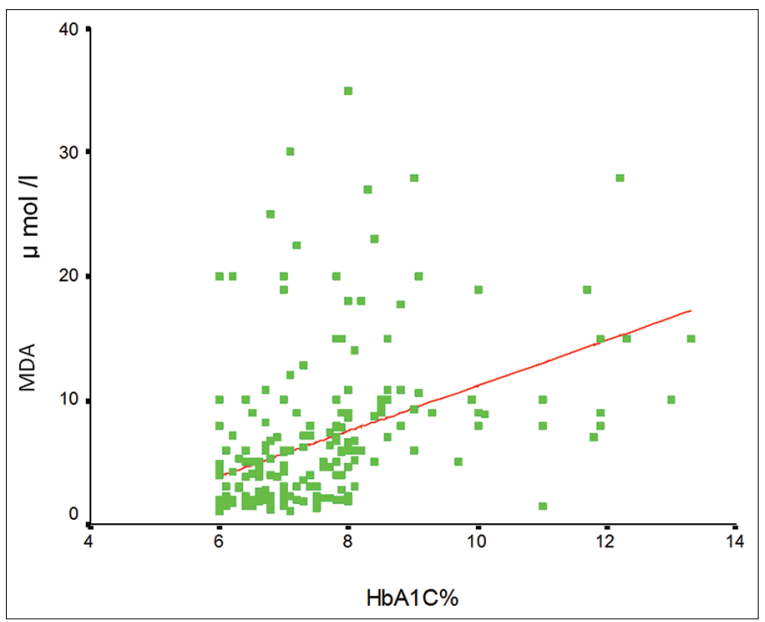

Fig. 2: Scatter plot shows the relationship between $\mathrm{HbA1c} \%$ and MDA of the test group $(\mathrm{n}=300)(\mathrm{r}=0.41, \mathrm{p}=0.01 *)$. *Significant relationship between the changes in $\mathrm{HbA1c} \%$ and serum MDA among the test group $(\mathrm{p}<0.05)$ could have a role as cofactors in the pathogenesis and complications of T2DM [14]. Mawatari et al. showed that MDA level was not correlated with the HbA1 [15]. There are many data suggest that MDA as a lipid peroxidation indicator is higher in uncontrolled diabetes probably due to chronic high blood sugar followed by higher oxidative stress [16]. Our study also examined the effect of HbA1c with Vitamin C among T2DM and found there was significant correlation between HbA1c\% antioxidant Vitamin C. The result of this study is similar to the findings of the study conducted by Al Azzam et al. and concluded that oral supplementation of Vitamin $\mathrm{C}$ as an adjuvant with antidiabetic drugs may be of particularly attractive therapeutic effect in the treatment of T2DM [1]. Many studies have shown a decreased Vitamin C level in Type 2 diabetic patients, and this finding supported the relationship between HbA1c percent and antioxidant Vitamin C. Another study by Sridulyakul et al. reported that the significant decrease which was noted in the $\mathrm{HbA1c}$ in patients supplemented with Vitamin $\mathrm{C}$ and concluded that Vitamin C supplementation could reverse diabetes-induced endothelial cell dysfunction in mesenteric microcirculation [17]. We found significant correlation between $\mathrm{HbA1c} \%$ and plasma Vitamin E. This finding is consistent with many studies and concluded that Vitamin E supplementation was able to improve the already existing oxidative

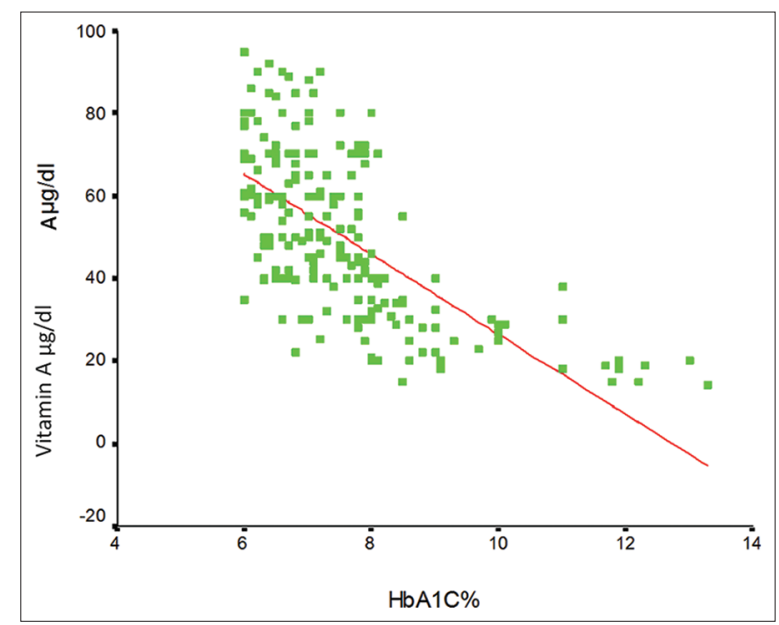

Fig. 3: Scatter plot shows the relationship between $\mathrm{HbA1c} \%$ and serum Vitamin $A$ of the test group $(n=300)(r=0.67, p=0.001 *)$. .*Significant relationship between the changes in $\mathrm{HbA1c} \%$ and serum Vitamin A among the test group $(p<0.05)$

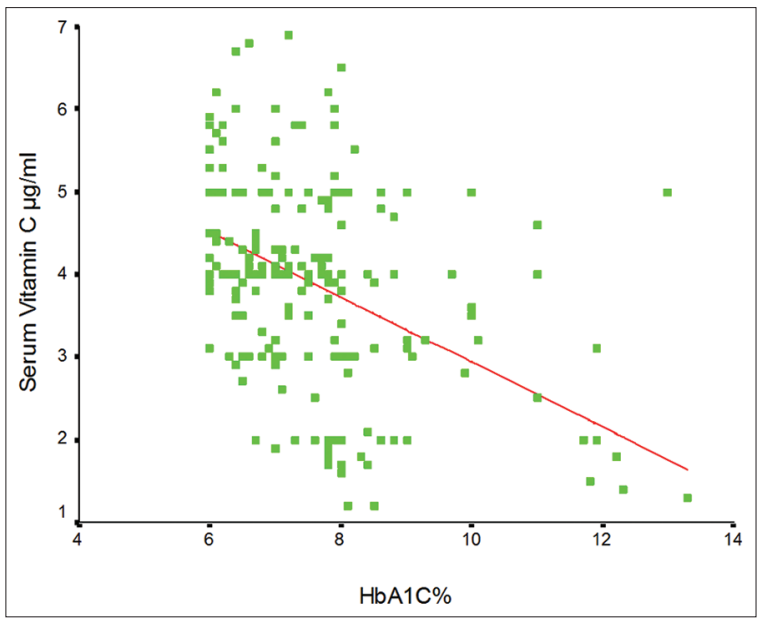

Fig. 4: Scatter plot shows the relationship between $\mathrm{HbA1c} \%$ and serum Vitamin $C$ of the test group $(n=300)(r=0.45, p=0.01 *)$.

.*Significant relationship between the changes in $\mathrm{HbA1c} \%$ and serum Vitamin $C$ among the test group $(p<0.05)$ 


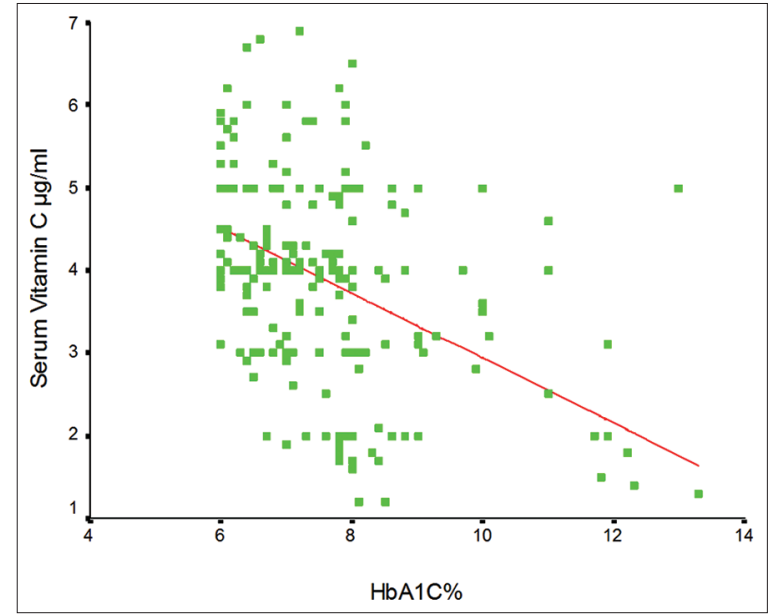

Fig. 5: Scatter plot shows the relationship between $\mathrm{HbA1c} \%$ and serum Vitamin $E$ of the test group $(n=300)(r=0.66, p=0.001 *)$. *Significant relationship between the changes in $\mathrm{HbA1c} \%$ and serum Vitamin $E$ among the test group $(p<0.05)$

stress in Type 2 diabetic patients $[18,19]$. Our result supported by the data from some studies suggests that Vitamin E supplements may lower HbA1c levels in patients with inadequate glycemic control [20]. We found significantly correlation between $\mathrm{HbA} 1 \mathrm{c} \%$ and plasma Vitamin A. Our finding is consistent with several studies which conducted among Type 2 diabetic patients [21,22]. There is link between diabetes and deficient of Vitamin A levels indicating Vitamin A supplementation may have a role in T2DM biology [23]. In general, antioxidant Vitamins $\mathrm{A}, \mathrm{C}$, and $\mathrm{E}$ are found decreased in diabetic subjects, possibly due to an increased need to control the excessive oxidative stress produced by abnormalities in glucose metabolism [24]. This alteration in antioxidants vitamins metabolism is related to increased values of glycated hemoglobin. Our study has many limitations: These include the relatively small sample size, potential markers such as levels of reduced glutathione (GSH), copper, magnesium, and Vitamin D.

\section{CONCLUSION}

The present study indicates that the HbA1c levels were found to be correlated positively with plasma levels of MDA, antioxidant Vitamins $\mathrm{A}, \mathrm{E}$, and C. According to the finding, we suggest that the estimation of MDA, HbA1c, and antioxidant vitamins could be helped in effective control and prevention among Type 2 diabetes patients.

\section{AUTHOR'S CONTRIBUTION}

There is no conflict of interests between authors; all three authors have made substantial contributions to conception and design, analysis, and interpretation of data. All authors have participated in drafting and revising the article and have given their final approval for submission.

\section{ACKNOWLEDGMENT}

We are grateful to all for participating in our study. Moreover, special thanks to the staff of advanced diagnostic center for routine follow-up in Sudan.

\section{REFERENCES}

1. Al Azzam KM. Effect of vitamin C on blood glucose and glycosylated hemoglobin in Type II diabetes mellitus. WJAC 2015;7:6-8.
2. Naqvi S, Naveed S, Ali Z, Ahmad SM, Asadullah R, Raj H, et al. Correlation between glycated hemoglobin and triglyceride level in Type 2 diabetes mellitus. Cureus 2017;9:1-9.

3. Moussa SA. Oxidative stress in diabetes mellitus. Romanian J Biophys 2008; 18:225-36

4. Szaleczky E, Prechl J, Feher J, Somogyi A. Alterations in enzymatic antioxidant defence in diabetes mellitus - a rational approach. Postgrad Med J 1999;75:13-7.

5. Prynne CJ, Wagemakers JJ, Stephen AM, Wadsworth ME. Meat consumption after disaggregation of meat dishes in a cohort of British adults in 1989 and 1999 in relation to diet quality. Eur J Clin Nutr 2009;63:660-6.

6. Saleh J. Glycated hemoglobin and its spinoffs: Cardiovascular disease markers or risk factors. World J Cardiol 2015;7:449-53.

7. Mohammad H, Girish T, Sarvajeet K, Surulivelrajan M. Correlation of glycosylated hemoglobin levels with fasting and postprandial glucose in South Indian Type 2 diabetic patients. Int J Pharm Pharm Sci 2016;8:285-8.

8. Muslih RK, Al-Nimer MS, Al-Zamely OM. The study level of malondialdehyde after activation with $(\mathrm{H} 2 \mathrm{o} 2$ and $\mathrm{CuSO} 4)$ and inhibitition of desferoxamine and molsidomine in the serum of patients with acute myocardial infection. Nat J Chem 2002;5:139-43.

9. Satillo M, Makoni T. A highly sensitive colorimetric determination of serum zinc using water-soluble pyridylazo dye. Clin Chim Acta 1982;120:127-35.

10. Thambiah SC, Samsudin IN, George E. Relationship between dyslipidaemia and glycaemic status in patients with Type 2 diabetes mellitus. Malays J Pathol 2016;38:123-30.

11. Ko GT, Chan JC, Woo J, Lau E, Yeung VT, Chow CC, et al. Glycated haemoglobin and cardiovascular risk factors in Chinese subjects with normal glucose tolerance. Diabet Med 1998;15:573-8.

12. Mehravar F, Mansournia MA, Abolhassani M, Holakouie NK, Nasli EE. The association between serum lipids profile and $\mathrm{HbAlc}$ in Type 2 diabetes mellitus in Tehran. Int J Epidemiol Res 2017;4:125-33.

13. Mubashra B, Adliah MA, Mohd MB. Lipid profile patterns and association between glycated haemoglobin $(\mathrm{HbA1C})$ and atherogenic index of plasma (AIP) in diabetes patients at a tertiary care hospital in Malaysia. Int J Pharm Pharm Sci 2017;9:150-4.

14. Salem M, Kholoussi S, Kholoussi N, Fawzy R. Malondialdehyde and trace element levels in patients with Type 2 diabetes mellitus. Arch Hellenic Med 2011;28:83-8.

15. Mawatari S, Saito K, Murakami K, Fujino T. Absence of correlation between glycated hemoglobin and lipid composition of erythrocyte membrane in Type 2 diabetic patients. Metabolism 2004;53:123-7.

16. Zarei M, Farahnak Z, Hosseinzadeh MJ, Javanbakht MH, Hosseinzadeh P, Derakhshanian $\mathrm{H}$, et al. Lipid peroxidation and antioxidant enzymes activity in controlled and uncontrolled Type 2 diabetic patients. ARYA Atheroscler 2016; 12:118-23.

17. Sridulyakul P, Chakraphan D, Patumraj S. Vitamin C supplementation could reverse diabetes-induced endothelial cell dysfunction in mesenteric microcirculation in STZ-rats. Clin Hemorheol Microcirc 2006;34:315-21.

18. Nweke IN, Ohaeri OC, Ezeala CC. Effect of vitamin on malondialdehyde and glutathione levels in Type 2 diabetic Nigerians. Internet J Nutr Wellness 2009;7:1-4

19. Mahboob M, Rahman MF, Grover P. Serum lipid peroxidation and antioxidant enzyme levels in male and female diabetic patients. Singapore Med J 2005;46:322-24.

20. Sinclair AJ, Taylor PB, Lunec J, Girling AJ, Barnett AH. Low plasma ascorbate levels in patients with Type 2 diabetes mellitus consuming adequate dietary vitamin C. Diabetic Med 1994;11:893-8.

21. Montazerifar F, Hashemi M, Karajibani M, Dikshit M. Natural Antioxidants and oxidative stress markers in hemodialysis patients. Hong Kong J Nephrol 2010;1:57-61.

22. Ha TK, Sattar N, Talwar D, Cooney J, Simpson K, O'Reilly DS, et al. Abnormal antioxidant vitamin and carotenoid status in chronic renal failure. QJM 1996;89:765-9.

23. Iqbal S, Naseem I. Role of vitamin A in Type 2 diabetes mellitus biology: Effects of intervention therapy in a deficient state. Nutrition 2015;31:901-7.

24. Mandavia CH, Aroor AR, De Marco VG, Sowers JR. Molecular and metabolic mechanisms of cardiac dysfunction in diabetes. Life Sci 2013;92:601-8. 